University of Wollongong

Research Online

Faculty of Engineering and Information

Faculty of Engineering and Information

Sciences - Papers: Part A

Sciences

$1-1-2014$

\title{
Study on hot-working behavior of high carbon steel / low carbon steel composite material using processing map
}

Xingjian Gao

University of Wollongong, xg306@uowmail.edu.au

Zhengyi Jiang

University of Wollongong, jiang@uow.edu.au

Dongbin Wei

University of Technology Sydney, dwei@uow.edu.au

Sihai Jiao

Baosteel, Baosteel Research Institute

Dengfu Chen

Chongqing University

Follow this and additional works at: https://ro.uow.edu.au/eispapers

Part of the Engineering Commons, and the Science and Technology Studies Commons

Research Online is the open access institutional repository for the University of Wollongong. For further information contact the UOW Library: research-pubs@uow.edu.au 


\title{
Study on hot-working behavior of high carbon steel / low carbon steel composite material using processing map
}

\begin{abstract}
The high carbon steel (HCS)/low carbon steel (LCS) laminated composite made by centrifugal casting technology was subjected to hot compression tests on Gleeble 3500 thermomechanical simulator in a range of temperatures (800-1100 oC) and strain rates (0.02-10 s-1). The hot-working behavior of the laminate was characterised by analysing the flow stress-strain curves and constructing the processing map based on dynamic materials model via superimposing efficiency of power dissipation and flow instability maps. The safe and unsafe processing conditions were identified in the processing map which was validated by microstructural examinations. Banded microstructure and micro-shear cracks occurred in the unsafe domains were responsible for the flow instability, while dynamic recrystallisation in stable domains with high efficiency of power dissipation imparted a good workability to the laminate. The optimum hot-working parameters were determined to be: (i) 800-1050 oC and 0.02-0.04 s-1, (ii) 800-1045 $\mathrm{OC}$ and $2.5-10 \mathrm{~s}-1$ and (iii) $1050-1100 \mathrm{oC}$ and 0.02-2.5 s-1.
\end{abstract}

\section{Keywords}

low, composite, material, study, hot, processing, working, map, behavior, high, carbon, steel

\section{Disciplines}

Engineering | Science and Technology Studies

\section{Publication Details}

Gao, X., Jiang, Z., Wei, D., Jiao, S. \& Chen, D. (2014). Study on hot-working behavior of high carbon steel / low carbon steel composite material using processing map. Key Engineering Materials, 622-623 330-339. 


\title{
Study on hot-working behavior of high carbon steel / low carbon steel composite material using processing map
}

\author{
Xingjian $\mathrm{Gao}^{1,2, \mathrm{a}}$, Zhengyi Jiang ${ }^{1, \mathrm{~b},{ }^{*}}$, Dongbin $\mathrm{We}^{1,3, \mathrm{c}}$, Sihai Jiao ${ }^{4, \mathrm{~d}}$, \\ Dengfu Chen ${ }^{2, e}$ \\ ${ }^{1}$ School of Mechanical, Materials and Mechatronic Engineering, University of \\ Wollongong, Wollongong NSW 2522, Australia \\ ${ }^{2}$ College of Materials Science and Engineering, Chongqing University, Chongqing \\ 400044, China \\ ${ }^{3}$ School of Electrical, Mechanical and Mechatronic Systems, University of \\ Technology, Sydney NSW 2007, Australia \\ ${ }^{4}$ Baosteel Research Institute, Baoshan Iron \& Steel Co., Ltd., Shanghai 200941, \\ China \\ axg306@uowmail.edu.au, bjiang@uow.edu.au, cdwei@uow.edu.au, \\ dshjiao@baosteel.com, ecchendfu@cqu.edu.cn, "Corresponding author
}

Keywords: Laminated composite; Processing map; Work hardening; Dynamic softening

\begin{abstract}
The high carbon steel (HCS)/low carbon steel (LCS) laminated composite made by centrifugal casting technology was subjected to hot compression tests on Gleeble 3500 thermomechanical simulator in a range of temperatures (800-1100 ${ }^{\circ} \mathrm{C}$ ) and strain rates $\left(0.02-10 \mathrm{~s}^{-1}\right)$. The hot-working behavior of the laminate was characterised by analysing the flow stress-strain curves and constructing the processing map based on dynamic materials model via superimposing efficiency of power dissipation and flow instability maps. The safe and unsafe processing conditions were identified in the processing map which was validated by microstructural examinations. Banded microstructure and micro-shear cracks occurred in the unsafe domains were responsible for the flow instability, while dynamic recrystallisation in stable domains with high efficiency of power dissipation imparted a good workability to the laminate. The optimum hot-working parameters were determined to be: (i) $800-1050{ }^{\circ} \mathrm{C}$ and $0.02-0.04 \mathrm{~s}^{-1}$, (ii) $800-1045{ }^{\circ} \mathrm{C}$ and $2.5-10 \mathrm{~s}^{-1}$ and (iii) $1050-1100{ }^{\circ} \mathrm{C}$ and $0.02-2.5 \mathrm{~s}^{-1}$.
\end{abstract}

\section{Introduction}

As one of the most famous laminated metal composites (LMCs), Damascus steel, which is common to select a low carbon steel (LCS) and a high carbon steel (HCS) for the two kinds of raw materials [1], exhibits a unique charm of LMCs by its 
aesthetic appearance. Meanwhile, with the increasing requirement on development of advanced materials of higher mechanical properties and fabrication processes of cost efficiency, it also inspires engineers and researchers to extend the applications of LCS and HCS by combining their dissimilar advantages. It is well known that HCS not only has attractive strength/ductility balance and high wear resistance, but also suffers from deteriorated weldability because of the elevated carbon content [2, 3]. While LCS contains less carbon leading to a relatively low strength but excellent weldability. So a focus of the promising research was to produce HCS/LCS laminated composite for desired combination [4-6]. However, the coexistence of softer LCS and harder HCS in the structure of the laminate makes the hot deformation behavior different from that of the monolithic steels. Bonding of dissimilar steels into a single laminate inevitably creates interface or inhomogeneity which may result in discontinuity of stress distribution. Therefore, it is of great significance to study the hot-working characteristics of HCS/LCS laminated composite for obtaining defect-free productions.

Processing map has been demonstrated to be a very powerful tool for optimising hot-workability and controlling the microstructure of metals, in which not only the microstructural evolution mechanism and the flow instability domains are revealed but also the optimum deformation ranges of temperature, strain and strain rate can be identified [7-16]. Over the past 10 years, the investigations on development of processing map for metal matrix composites (MMCs) were significant. For instance, Cavaliere et al. [12] studied the mechanical response of a particulate reinforced 2618/Al2O3/20p MMC using processing maps based on the Prasad and Gegel criteria. Ganesan et al. [13], Ramanathan et al. [14] and Rajamuthamilselvan et al. [8] proposed the processing maps for $6061 \mathrm{Al} / 15 \% \mathrm{SiCp}, 2124 \mathrm{Al} / \mathrm{SiCp}$ and 7075 $\mathrm{Al} / 15 \%$ SiCp MMCs, respectively. Liu et al. [15] analysed the hot deformation behavior of TiCp/AZ91D magnesium MMC by means of hot compression and processing map, and most recently, Huang et al. [16] predicted the optimal hot-working parameters for the novel TiBw/Ti64 MMC with the help of processing maps combined with microstructure analysis. Although many efforts have been made to address the hot-workability of different kinds of MMCs using processing maps, little attention has paid to LMCs, especially to HCS/LCS laminated composite.

The aim of this work is to study the hot-working behavior of HCS/LCS laminated composite by hot compression tests. Following the compression tests, the processing map is developed on the basis of dynamic materials model (DMM) [9] to indicate the safe and unsafe deformation domains. In order to confirm the flow stability and instability regions, microstructural examination of the test samples is also carried out.

\section{Experimental procedure}

The chemical compositions of HCS and LCS selected in this investigation are given in Table 1. Centrifugal casting technology was employed to fabricate the laminated composite with HCS as the inner layer and LCS as the outer layer. The detailed procedure and unique microstructural characteristics due to the formation of the interface have been reported in our previous work [6]. As shown in Fig. 1, the starting 
microstructure of the as-cast laminate consisted of four different etched layers, which represented the typical microstructural features of LCS region (Fig. 1(f)), interface region (Fig. 1(c)), fully pearlitic HCS region (Fig. 1(d)) and proeutectoid-ferritic/pearlitic HCS region (Fig. 1(a)), respectively. Such a unique microstructural distribution probably results in discontinuity of stress distribution during the plastic deformation.

Table 1 Chemical compositions of HCS and LCS (wt. \%)

\begin{tabular}{ccccccccccc}
\hline Steels & $\mathrm{C}$ & $\mathrm{Si}$ & $\mathrm{Mn}$ & $\mathrm{P}$ & $\mathrm{S}$ & $\mathrm{Ni}$ & $\mathrm{Cr}$ & $\mathrm{Cu}$ & $\mathrm{Ti}$ & $\mathrm{V}$ \\
\hline HCS & 0.63 & 0.60 & 0.31 & 0.031 & 0.0165 & 0.01 & 0.011 & 0.012 & 0.012 & 0.0055 \\
LCS & 0.122 & 0.22 & 0.37 & 0.023 & 0.015 & 0.01 & 0.011 & 0.009 & $<0.002$ & $<0.003$ \\
\hline
\end{tabular}
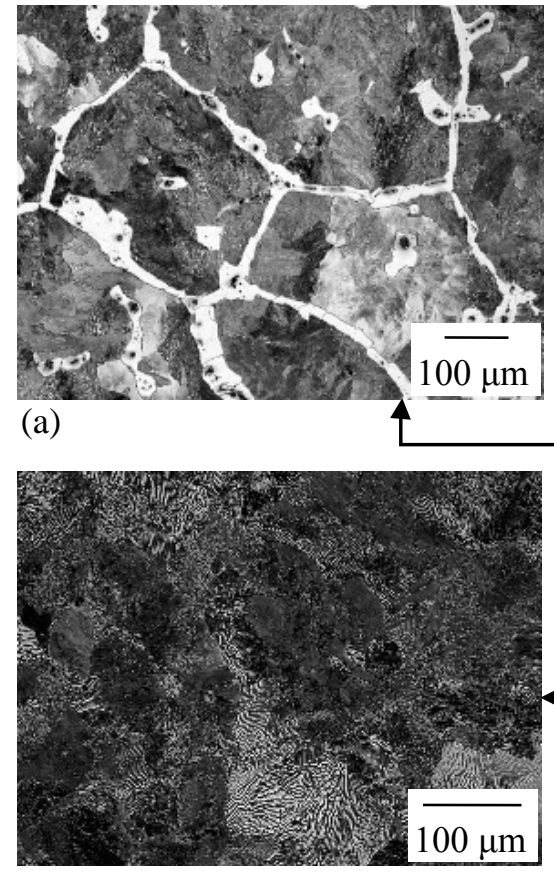

(d)

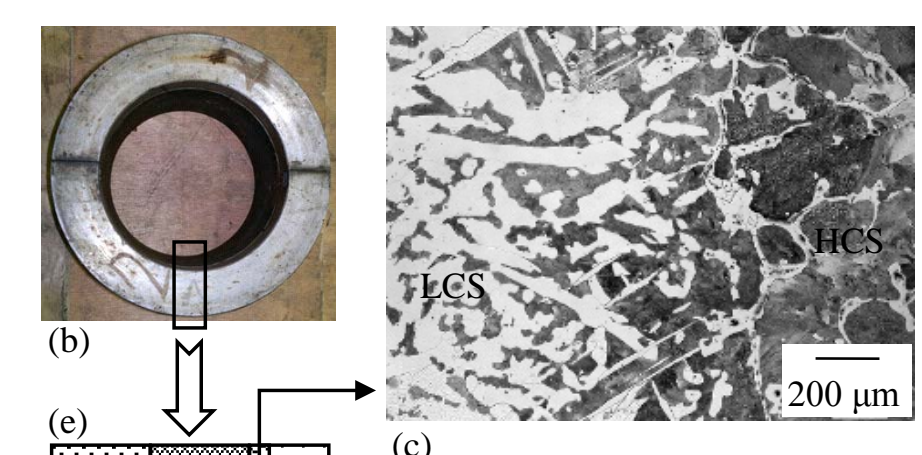

(c)

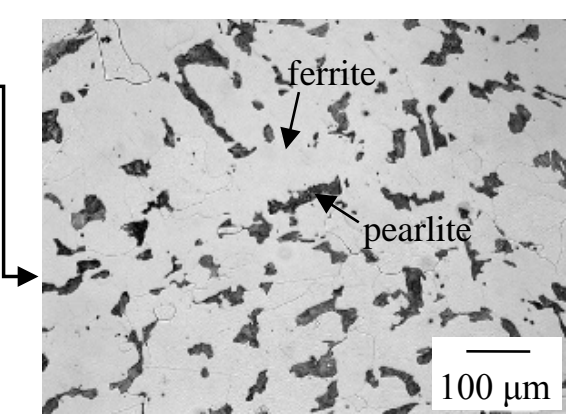

(f)

Fig. 1 The starting microstructure of the as-cast laminate. (a) proeutectoid-ferritic/pearlitic HCS region, (b) picture of the laminated ingot, (c) interface region, (d) fully pearlitic HCS region, (e) sketch of different etched layers, (f) LCS region.

The compression test cylindrical samples with the diameter of $10 \mathrm{~mm}$ and the height of $20 \mathrm{~mm}$ were machined from the ingot, in which the interface is perpendicular to the axis and the thickness of LCS and HCS layers are about 5 and 15 $\mathrm{mm}$, respectively. A series of isothermal compression tests were performed on a Gleeble 3500 thermomechanical simulator at temperatures of 800, 900, 1000 and $1100{ }^{\circ} \mathrm{C}$ and at the strain rates of $0.02,0.1,1$ and $10 \mathrm{~s}^{-1}$. Prior to testing, graphite was applied on both contacting surfaces of samples to reduce the friction coefficient between samples and anvils. All samples were heated up to the deformation 
temperature at a constant heating rate of $20{ }^{\circ} \mathrm{C} / \mathrm{s}$ and soaked for $60 \mathrm{~s}$, afterwards $60 \%$ of height reduction was conducted with a certain strain rate before the samples were quenched by air jet. Following this, the deformed samples were sectioned parallel to the compression axis and the cross-section was polished for metallographic examination by etching with $2.5 \%$ Nital solution. Microstructural evolution through hot deformation was observed using optical microscope (OM) and scanning electron microscope (SEM).

\section{Results and discussion}

Flow stress-strain curves. Typical true stress-strain curves obtained at temperature of $1000{ }^{\circ} \mathrm{C}$ and strain rate of $0.1 \mathrm{~s}^{-1}$ are shown in Fig. 2. It is clearly noticed that the flow stress level of HCS/LCS laminated composite is sensitively dependent on strain rate and temperature, because the true stress increases significantly with an increase of strain rate and decrease of temperature. For all the compression cases, true stress rises steeply up to a true strain of 0.02-0.04 and then keeps ascending at a slower rate towards to a peak stress value. The former phenomena indicates the work hardening dominated the deformation with an increase of dislocation density dramatically, while the latter one suggests a competition between the work hardening and dynamic softening ascribed to dynamic recovery (DRV) and dynamic recrystallisation (DRX). The decrease of true stress over the peak value demonstrates the flow softening mechanism.
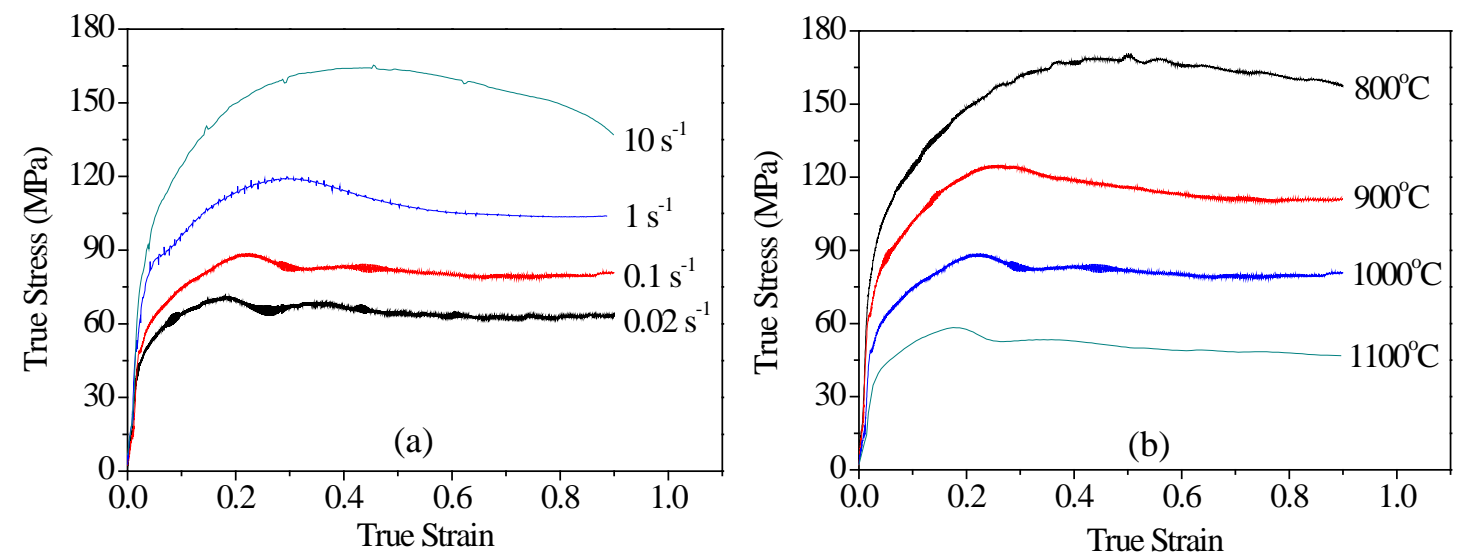

Fig. 2 Typical true stress-strain curves obtained at different conditions. (a) $1000{ }^{\circ} \mathrm{C}$,

$$
\text { (b) } 0.1 \mathrm{~s}^{-1} \text {. }
$$

In addition, it is also evident that the multi-peak behavior is observed at lower strain rates $\left(<1 \mathrm{~s}^{-1}\right)$ and higher temperatures $\left(>900{ }^{\circ} \mathrm{C}\right)$. Two reasons may respond to this issue. The first one is discontinuous DRX, which means the DRX process could not be completed before the next critical deformation happened. However, the further deformation of the partially DRX grains causes fresh work hardening that makes flow stress increase again. This theory has been proven in single metals $[17,18]$. In the present work, there perhaps has another reason which is the heterogeneity of plastic 
deformation in different constituents, i.e. softer LCS and harder HCS. A further investigation is required for this mechanism. In terms of higher strain rates $\left(\geq 1 \mathrm{~s}^{-1}\right)$ and lower temperatures $\left(\leq 900{ }^{\circ} \mathrm{C}\right)$, continuous DRX results in successive cycles of DRX process overlapped at a moment $[17,18]$. Therefore, a single-peak behavior is expected.

Processing map. Assuming the test sample is a dissipator of power during deformation, the processing map of HCS/LCS laminated composite was constructed based on DMM by analysing the true stress-strain data. DMM, which was first developed by Prasad et al. [9], is a continuum model considering the fundamental properties of continuum mechanics of large plastic flow and irreversible thermodynamics in a physical system modeling. In this model, the total power P (per unit volume) dissipated by the workpiece, i.e. the test sample in the present work, consists of two complementary parts of $G$ and $J$. The former represents the power dissipation in forms of temperature increase through plastic deformation, while the latter contains the energy consumption in metallurgical process such as DRV and DRX as well as defects formation. So the total power $\mathrm{P}$ absorbed by the workpiece during plastic flow is written as:

$$
P=G+J=\sigma \dot{\varepsilon}=\int_{0}^{\dot{\varepsilon}} \sigma d \dot{\varepsilon}+\int_{0}^{\sigma} \dot{\varepsilon} d \sigma
$$

where $\sigma$ is the instantaneous flow stress, $\dot{\varepsilon}$ is the applied strain rate. The correlation between $G$ and $J$ is determined by strain rate sensitivity m used to describe the power partition as the following equation:

$$
m=\frac{d J}{d G}=\frac{\dot{\varepsilon} d \sigma}{\sigma d \dot{\varepsilon}}=\frac{d \ln \sigma}{d \ln \dot{\varepsilon}}
$$

Combining Eqs. (1) - (2) and after integration, $J$ co-content is converted as follows:

$$
J=\frac{\sigma \dot{\varepsilon} m}{m+1}
$$

For an ideal linear dissipation, $m=1$ and $J=J_{\max }=P / 2$. So the efficiency of power dissipation of nonlinear dissipator during deformation can be defined as:

$$
\eta=\frac{J}{J_{\max }}=\frac{2 m}{m+1}
$$

The variation of $\eta$ with temperature and strain rate constitutes the power dissipation map (PDM). As previously mentioned, $J$ co-content is associated with microstructural evolution so that the PDM can depict the extent of power dissipation in different domains by specific microstructural changes and reveal the relevant mechanisms. In general, the safe domains for hot-working are met when $\eta$ is maximum [17]. Fig. 3(a) shows the PDM of HCS/LCS laminated composite after undergoing $60 \%$ of overall reduction. The contour numbers represent the percent efficiency of power dissipation.

In order to identify the regimes of flow instabilities in PDM, a continuum instability criterion [19] based on the extremum principles of irreversible thermodynamics as applied to large plastic flow was employed in current study. According to this criterion, flow instability occurs if:

$$
\xi(\dot{\varepsilon})=\frac{\partial \ln [m /(m+1)]}{\partial \ln \dot{\varepsilon}}+m \leq 0
$$


The variation of the instability parameter $\xi(\dot{\varepsilon})$ with temperature and strain rate constitutes the flow instability map (FIM). Fig. 3(b) shows the FIM of HCS/LCS laminated composite after suffering $60 \%$ of overall reduction, in which the negative contour values profile the instability regions.
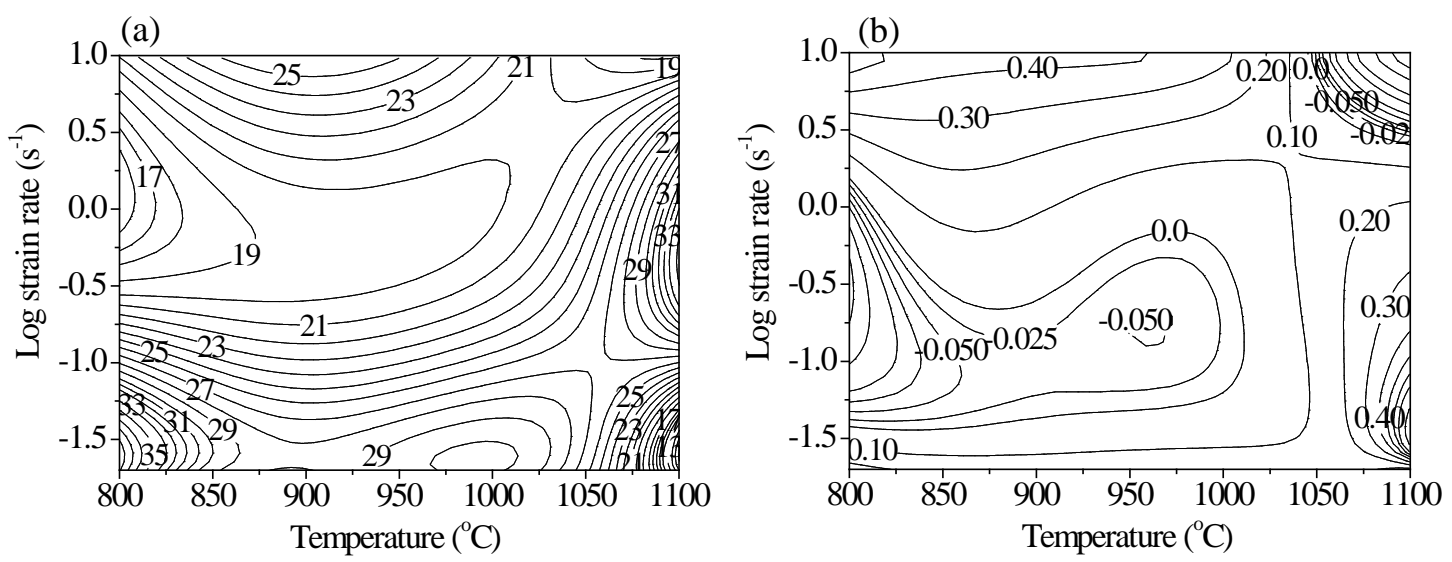

Fig. 3 Power dissipation map (a) and flow instability map (a) at true strain of 0.9.

The processing map, as shown in Fig. 4, was obtained by superimposing the PDM and FIM with true strain of 0.9. The gray patched regions represent the flow instability domains extracting from Fig. 3(b). It is clearly seen that there are two distinct domains with instable features. Domain I occurs in the temperature range from $800-1010{ }^{\circ} \mathrm{C}$ for a strain rate of $0.04-2.5 \mathrm{~s}^{-1}$, while domain II emerges in the temperature range of $1045-1100{ }^{\circ} \mathrm{C}$ and the strain rate varying from $2.5-10 \mathrm{~s}^{-1}$. Because the instable hot-working behavior usually results from adiabatic shear bands formation, flow localization, dynamic strain aging and defects generation such as voids and cracks [20], so domains I and II should be avoided during deformation. The microstructural characteristics of the test samples processing in these domains are discussed below.

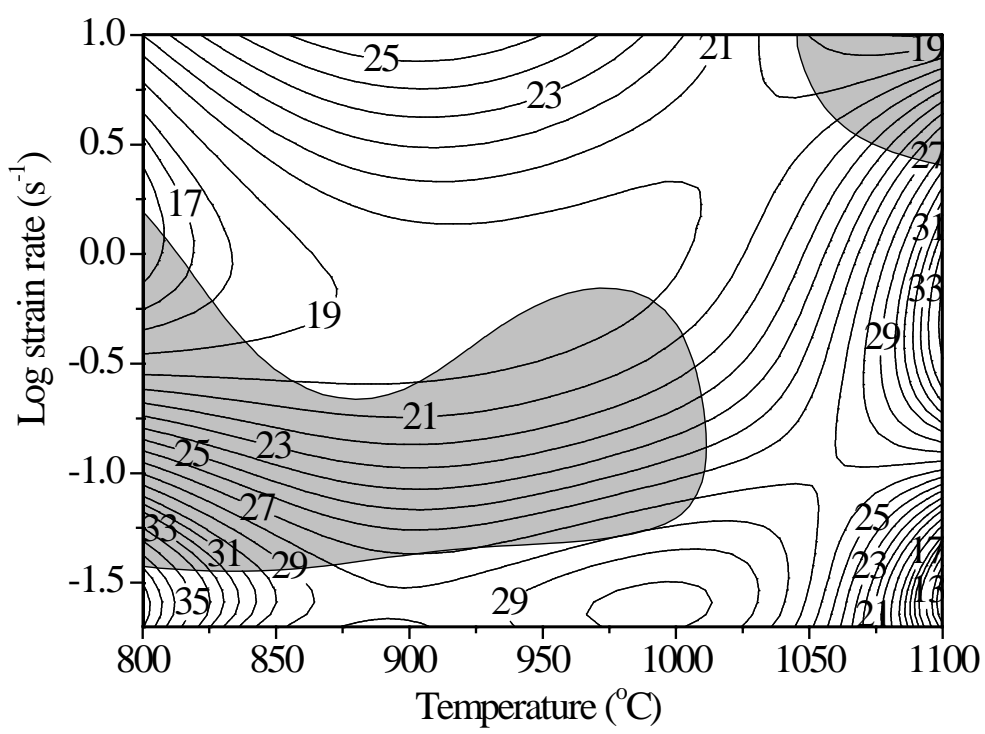


Fig. 4 Processing map of the HCS/LCS laminated composite at true strain of 0.9.

On the other hand, it is widely recognized that a high value of the efficiency of power dissipation usually corresponds to DRV and DRX, even though the unstable flow may also occur in high efficiency region. DRX is beneficial for hot-working process since a good intrinsic workability is provided by flow softening and microstructural reconstitution [13]. Consequently, the safe conditions for hot-working the HCS/LCS laminated composite consists of three desirable domains where $\xi(\dot{\varepsilon})$ is positive. These safe domains are: $800-1050{ }^{\circ} \mathrm{C}$ at $0.02-0.04 \mathrm{~s}^{-1}$ with a peak $\eta$ of $30 \%$, 800-1045 ${ }^{\circ} \mathrm{C}$ at $2.5-10 \mathrm{~s}^{-1}$ with a peak $\eta$ of $25 \%$ and $1050-1100{ }^{\circ} \mathrm{C}$ at $0.02-2.5 \mathrm{~s}^{-1}$ with a peak $\eta$ of $33 \%$.

Microstructures. To validate the domains of unsafe and safe conditions in the processing map, the microstructures of test samples at different conditions are characterised by OM and SEM. Fig. 5(a) and (b) show the ferrite/pearlite banded microstructures, which are perpendicular to the compression axis, in LCS and proeutectoid-ferritic/pearlitic HCS regions at $800{ }^{\circ} \mathrm{C} / 0.1 \mathrm{~s}^{-1}$, respectively. Many efforts have been done on the formation of such a structure and the microsegregation of alloying elements was found to be a common reason [21, 22]. But for the current study, the heterogeneity of plastic deformation in different constituents may be the real reason which demands a further investigation. However, this heterogeneous microstructure will be detrimental to the mechanical properties of materials such as impaired ductility and impact performance as well as cracking tendency [21, 22]. Therefore, hot-working process should be kept away from these conditions.
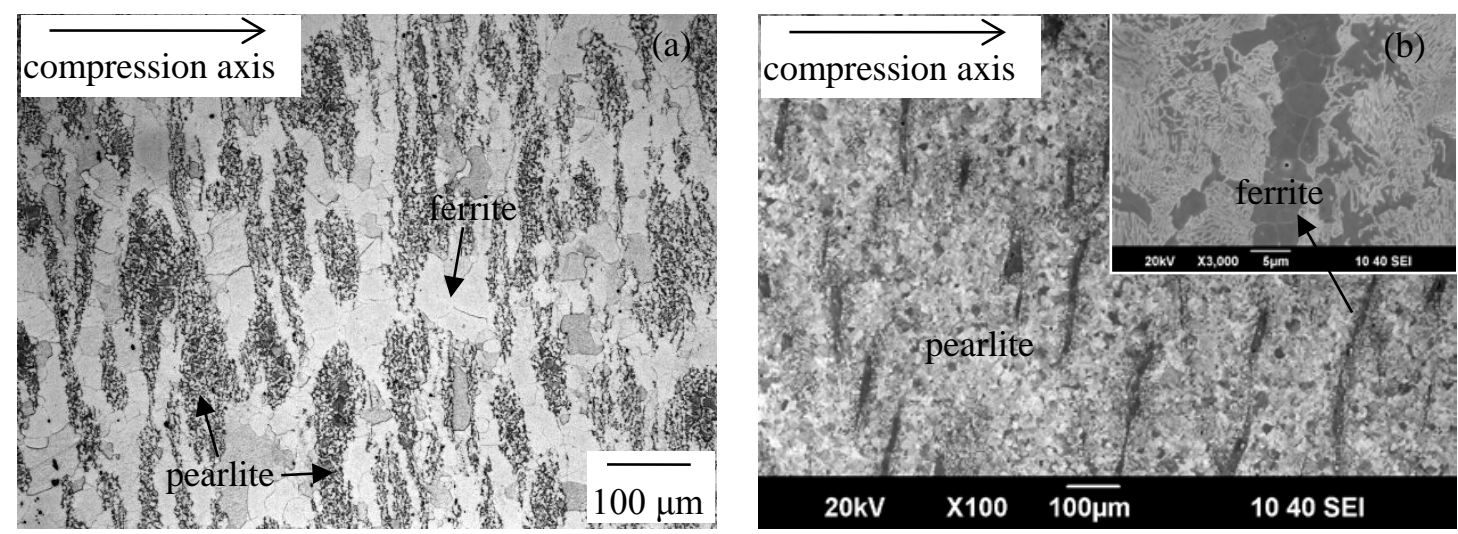

Fig. 5 Microstructures of the test sample compressed at $800{ }^{\circ} \mathrm{C} / 0.1 \mathrm{~s}^{-1}$. (a) LCS region, (b) proeutectoid-ferritic/pearlitic HCS region. 

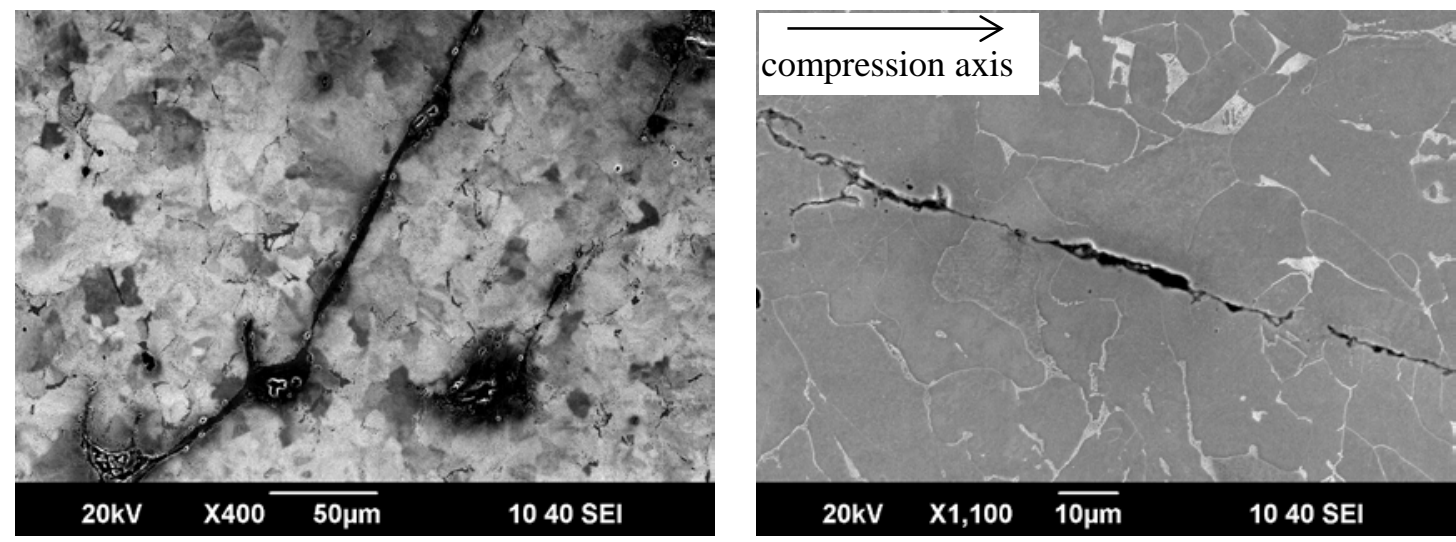

Fig. 6 Microstructures of the test samples compressed at $900{ }^{\circ} \mathrm{C} / 0.1 \mathrm{~s}^{-1}$ (a), 1100 ${ }^{0} \mathrm{C} / 10 \mathrm{~s}^{-1}$ (b).

The microstructures of the test samples compressed in other instability domains are demonstrated in Fig. 6. Fig. 6(a) and (b) show the micro-shear cracks occurred at an angle approximately 450 to the compression axis at $900{ }^{\circ} \mathrm{C} / 0.1 \mathrm{~s}^{-1}$ and $1100{ }^{\circ} \mathrm{C} / 10 \mathrm{~s}^{-1}$, respectively. For the former one, crack is found in proeutectoid-ferritic/pearlitic HCS region, while for the latter one it is in LCS region. This difference indicates different deformation resistances dominate the hot-working process in these two different conditions. A reasonable explanation for this difference is the discrepant mechanical properties of LCS and HCS in all temperatures and strain rates.
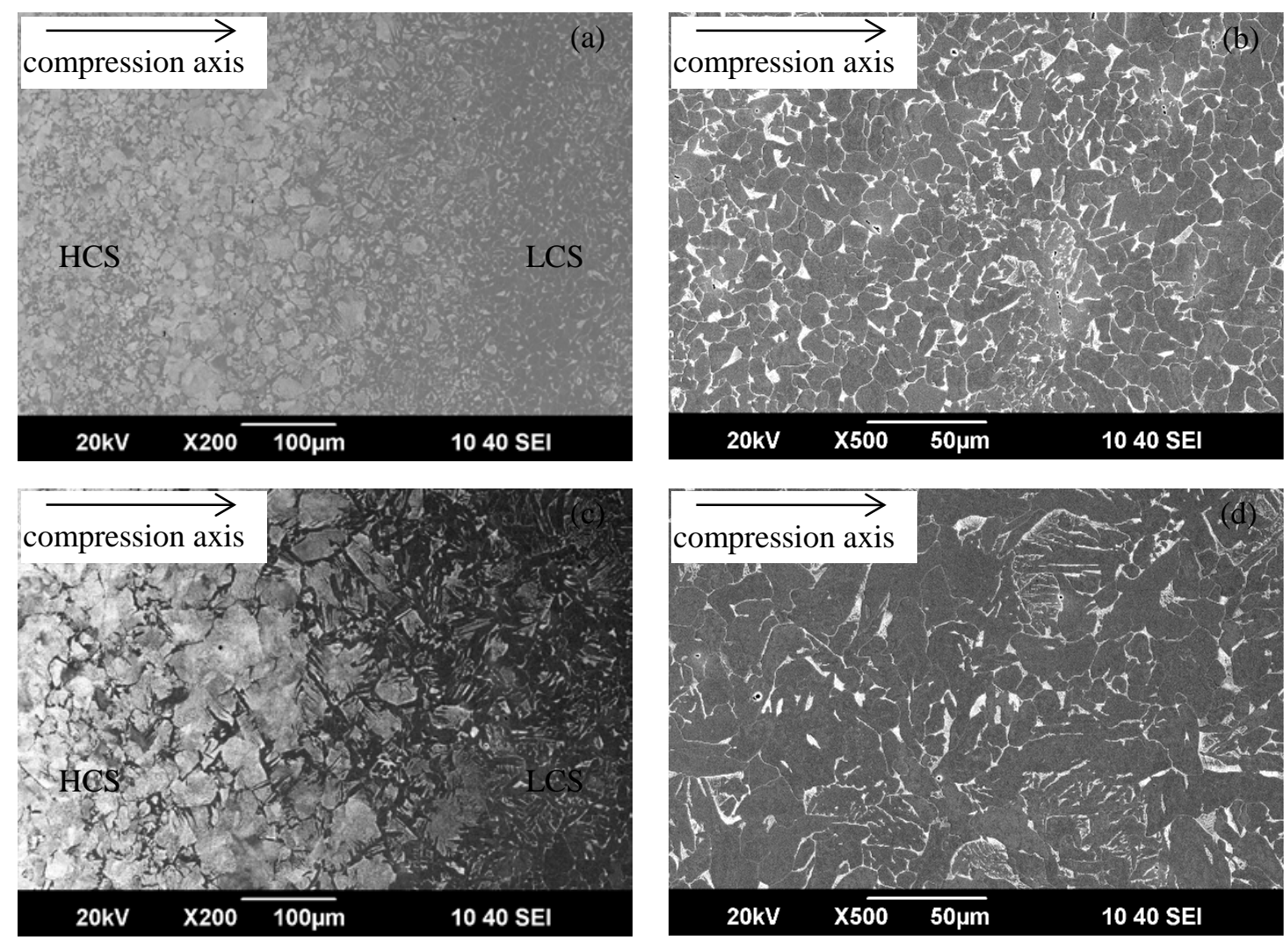

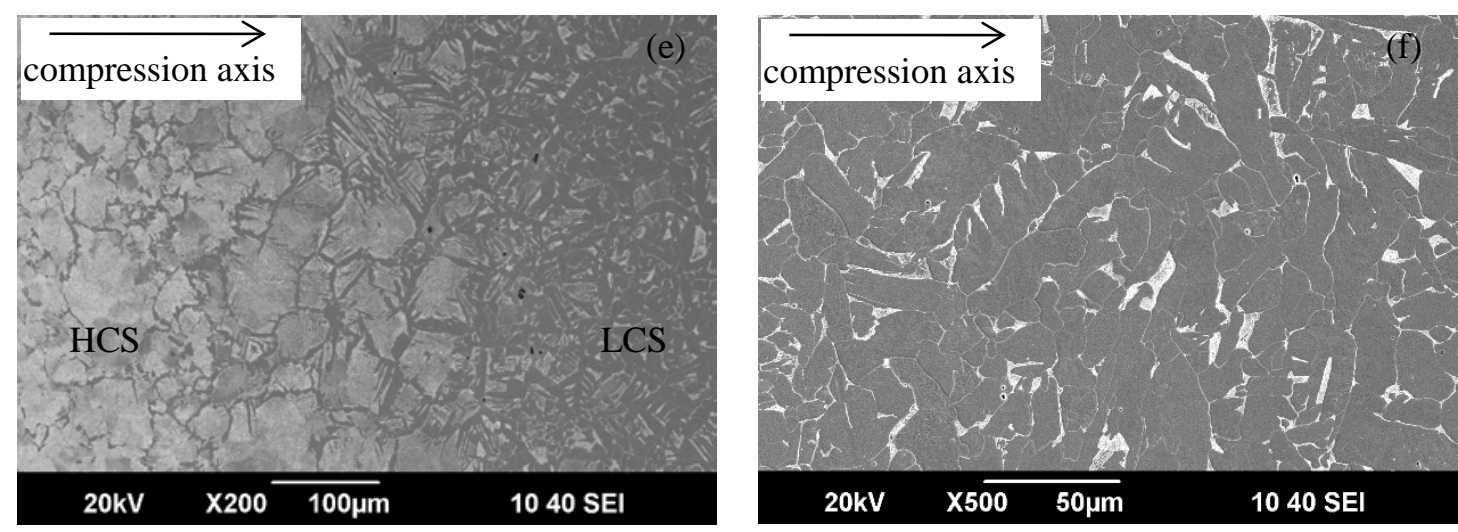

Fig. 7 Microstructures of the interface (a, c, e) and LCS (b, d, f) regions of the test samples compressed at $900{ }^{\circ} \mathrm{C} / 10 \mathrm{~s}^{-1}$ (a, b), $1000{ }^{\circ} \mathrm{C} / 0.02 \mathrm{~s}^{-1}$ (c, d), $1100{ }^{\circ} \mathrm{C} / 0.1 \mathrm{~s}^{-1}$ (e, f).

In the safe processing domains, the microstructures of the interface and LCS regions of the test samples compressed at $900{ }^{\circ} \mathrm{C} / 10 \mathrm{~s}^{-1}, 1000{ }^{\circ} \mathrm{C} / 0.02 \mathrm{~s}^{-1}$ and 1100 ${ }^{\circ} \mathrm{C} / 0.1 \mathrm{~s}^{-1}$ are shown in Fig. 7(a, b), (c, d) and (e, f), respectively. It can be seen that there are no instable features such as the banded microstructure, flow localization and cracks are observed in all the three cases. According to the research of Momeni et al. [17], the occurrence of DRX inhibits the formation of instable features because of dislocation annihilation and rearrangement as well as new strain-free grains generation during this process. In comparison to the initial microstructures as shown in Fig. 1(c) and (f), DRX grains in Fig. 7 are prominent. Moreover, the DRX grain size increases with an increase of temperature and decrease of strain rate. This is because the higher temperature and the lower strain rate provide the longer growth time to DRX grains. Fig.8 shows the variation of Zener-Hollomon parameter ( $Z$ parameter) with true strain of 0.9 when hot-working condition changes from 900 ${ }^{\circ} \mathrm{C} / 10 \mathrm{~s}^{-1}$ to $1100{ }^{\circ} \mathrm{C} / 0.1 \mathrm{~s}^{-1}$ through $1000{ }^{\circ} \mathrm{C} / 0.02 \mathrm{~s}^{-1}$. The $Z$ parameter was calculated using the true stress-strain data. A significant decrease of Ln $Z$ dropping from $\sim 35$ at $900{ }^{\circ} \mathrm{C} / 10 \mathrm{~s}^{-1}$ to $\sim 25$ at $1000{ }^{\circ} \mathrm{C} / 0.02 \mathrm{~s}^{-1}$ and $1100{ }^{\circ} \mathrm{C} / 0.1 \mathrm{~s}^{-1}$ is presented in Fig. 8. The previous researchers have concluded that the DRX grain size decreases with increasing $Z$ parameter [18, 23-25]. This growing tendency of DRX grains corresponds to the increase of peak $\eta$ from 25 to 33\% in the three desirable domains as shown in Fig. 4. 


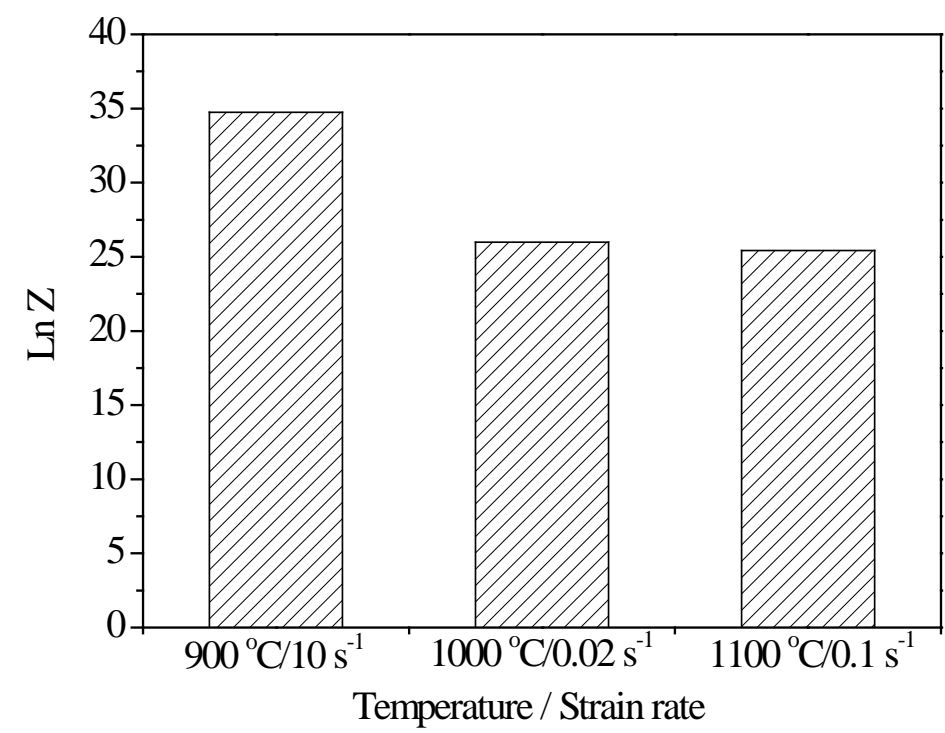

Fig. 8 Relationship between Ln $Z$ and hot-working conditions.

\section{Conclusions}

Hot-working behavior of laminated composite consisting of HCS and LCS was analysed by means of compression tests and processing map. The noticeable results are listed as follows:

(1) In the temperature range of $800-1100{ }^{\circ} \mathrm{C}$ for the strain rate varying from 0.02-10 s $\mathrm{s}^{-1}$, the flow stress of the HCS/LCS laminated composite decreases with an increase of hot-working temperature and increases with an increase of strain rate.

(2) On the basis of DMM, the processing map for the studied laminated composite was developed by superimposing the PDM and FIM. Safe and unsafe hot-working conditions are clearly identified using the processing map. The optimum processing parameters should be selected in the following three domains, viz: (i) $800-1050{ }^{\circ} \mathrm{C}$ and 0.02-0.04 s ${ }^{-1}$, (ii) 800-1045 ${ }^{\circ} \mathrm{C}$ and $2.5-10 \mathrm{~s}^{-1}$ and (iii) $1050-1100{ }^{\circ} \mathrm{C}$ and $0.02-2.5 \mathrm{~s}^{-1}$.

(3) In the instability domains, the instable mechanisms are revealed by the presence of the banded microstructure at $800{ }^{\circ} \mathrm{C} / 0.1 \mathrm{~s}^{-1}$ and micro-shear cracks at 900 ${ }^{\circ} \mathrm{C} / 0.1 \mathrm{~s}^{-1}$ and $1100{ }^{\circ} \mathrm{C} / 10 \mathrm{~s}^{-1}$. The occurrence of DRX in the stability domains with high efficiency of power dissipation provides a good workability for the studied laminated composite.

\section{Acknowledgements}

The first author also wishes to thank the China Scholarship Council (CSC) for supporting the current research work.

\section{References}

[1] J.D. Verhoeven, H.F. Clark: Mater. Charact. Vol. 41 (1998), p. 183.

[2] Y.D. Chung, H. Fujii, R. Ueji, N. Tsuji: Scripta Mater. Vol. 63 (2010), p. 223. 
[3] S.A. Khodir, Y. Morisada, R. Ueji, H. Fujii: Mater. Sci. Eng., A Vol. 558 (2012), p. 572.

[4] S. Sun, M. Pugh: Mater. Sci. Eng., A Vol. 300 (2001), p. 135.

[5] G.L. Xie, J. Liu, J.T. Han, X.G. Han: Journal of University of Science and Technology Beijing Vol. 32 (2010), p. 340. (In Chinese)

[6] X.J. Gao, Z.Y. Jiang, D.B. Wei, H.J. Li, S.H. Jiao, J.T. Han, in: The Fifth Baosteel Biannual Academic Conference, Shanghai, China, 2013, pp. C110-116.

[7] Y.V.R.K. Prasad, T. Seshacharyulu, S.C. Medeiros, W.G. Frazier: Mater. Manuf. Processes Vol. 15 (2000), p. 581.

[8] M. Rajamuthamilselvan, S. Ramanathan: Mater. Manuf. Processes Vol. 27 (2012), p. 260.

[9] Y.V.R.K. Prasad, H.L. Gegel, S.M. Doraivelu, J.C. Malas, J.T. Morgan, K.A. Lark, D.R. Baker: Metall. Trans. A Vol. 15A (1984), p. 1883.

[10] R. Ravi, Y.V.R.K. Prasad, V.V.S. Sarma, R.S. Raidu: Mater. Manuf. Processes Vol. 21 (2006), p. 756.

[11] R. Ravi, Y.V.R.K. Prasad, V.V.S. Sarma: Mater. Manuf. Processes Vol. 22 (2007), p. 846.

[12] P. Cavaliere, E. Cerri, P. Leo: Compos. Sci. Technol. Vol. 64 (2004), p. 1287.

[13] G. Ganesan, K. Raghukandan, R. Karthikeyan, B.C. Pai: Mater. Sci. Eng., A Vol. 369 (2004), p. 230.

[14] S. Ramanathan, R. Karthikeyan, G. Ganasen: Mater. Sci. Eng., A Vol. 441 (2006), p. 321.

[15] R. Liu, W. Cao, T.X. Fan, C.F. Zhang, D. Zhang: Mater. Sci. Eng., A Vol. 527 (2010), p. 4687.

[16] L.J. Huang, Y.Z. Zhang, L. Geng, B. Wang, W. Ren: Mater. Sci. Eng., A Vol. 580 (2013), p. 242.

[17] A. Momeni, K. Dehghani: Mater. Sci. Eng., A Vol. 527 (2010), p. 5467.

[18] M.J. Luton, C.M. Sellars: Acta Metall. Vol. 20 (1969), p. 1033.

[19] H. Ziegler, in: I.N. Sneedon, R. Hill (Eds.), Progress in Solid Mechanics, vol. 4, John Wiley and Sons, New York, 1963, pp. 63-193.

[20] Y.B. Yang, Z.M. Zhang, X. Zhang: Mater. Sci. Eng., A Vol. 558 (2012), p. 112.

[21] F.A. Khalid, M. Farooque, A. ul Haq, A.Q. Khan: Mater. Sci. Technol. Vol. 15 (1999), p. 1209.

[22] F.G. Caballero, A. Garcia-Junceda, C. Capdevila, C. Garcia de Andres: Mater. Trans., JIM Vol. 47 (2006), p. 2269.

[23] J.P. Sah, G.J. Richardson, C.M. Sellars: Metal Sci. Vol. 8 (1974), p. 325. 
[24] M. Ueki, S. Horie, T. Nakamura: Mater. Sci. Tech. Vol. 3 (1987), p. 329.

[25] T. Seshacharyulu, S.C. Medeiros, W.G. Frazier, Y.V.R.K. Prasad: Mater. Sci. Eng. A Vol. 325 (2002), p. 112. 